Applied Mathematical Sciences, Vol. 7, 2013, no. 110, 5457 - 5462

HIKARI Ltd, www.m-hikari.com

http://dx.doi.org/10.12988/ams.2013.38454

\title{
Mathematical Modeling of Development and
}

\section{Reconciling Cooperation Programs between}

\section{Natural Monopoly and Regional Authorities}

\author{
Sergey Vikharev \\ Ural Federal University \\ Office 607, Turgeneva str. 4, Ekaterinburg, Russia, 620075 \\ sergey@viharev.com
}

Copyright @ 2013 Sergey Vikharev. This is an open access article distributed under the Creative Commons Attribution License, which permits unrestricted use, distribution, and reproduction in any medium, provided the original work is properly cited.

\begin{abstract}
As it is shown in the [1], the interaction between the natural monopoly (next NM) and the region is expedient to be carried out on the basis of a joint development railway transport program in this region. In fact, a decision to launch a project in a certain cooperation program configuration adds up to comparison of components efficiencies, included into the project, and proposed projects influence to the transport constituent of the region [1-3]. At the same time, the project configuration is an investment structure into ongoing project by stakeholders and, hence, this is a structure of incomes as consequences of project implementation.

It should to be noted that there are some projects with low efficiency for one of the involved into the project parties. Despite this, these projects are implemented successfully in the case of all involved parties cooperation. This phenomenon cannot be explained within the frameworks of obviously unfavorable project to one of the parties. Such projects can be both the preparatory project for implementation the bigger one with further expenses compensation and the element of compromise in agreeing the whole complex of projects that are balanced, mutually beneficial and effective for all the participants.
\end{abstract}

Keywords: Developing a cooperation program, Mathematical modeling, Pareto efficiency 


\section{Formalization of the appropriate configuration program choice}

Developing a cooperation program or even a certain project, the responsible department NM is guided by corresponding ideas about current and strategic Company's interests in the region, regional economic situation, regional interests in the railway transportation and etc. Possible revenues from each certain project are calculated. The more exact the initial and forecast data are the more balanced, thoughtful and effective decision will be made.

During the research of quality complex characteristics and interaction structure of the NM and regions, the effectiveness ratio was developed. This ratio allows evaluating effectiveness of both the implemented projects and the projects that require making a decision concerning implementation.

The baseline data taken into account to solve a task of appropriate configuration program choice are the following:

$n$ - the number of projects implementing the interests of a NM and a region within the current period;

$d_{i}$ - the total amount of funds required for the i-project implementation, where $i=1,2, \ldots, n$;

$\underline{a}_{i}$ - the minimum amount that must be sent to the i-project of a NM to confirm a fact of participation in cooperation for this project, $i=1,2, \ldots, n$. Let's note that there are some items of cooperation program that fail to make a profit for NM themselves, however they have significant influence to the implementation of the whole cooperation program.

$\bar{a}_{i}$ - the maximum amount that can be invested in the i-project by a NM, $i=1,2, \ldots, n$;

$A$ - the maximum amount that can be invested in all project of a concur program by a NM;

$\underline{b}_{i}$ - the minimum amount that can be invested in the i-project by the regional administration, $i=1,2, \ldots, n$

$\bar{b}_{i}$ - the maximum amount that can be invested in the i-project by the regional administration, $i=1,2, \ldots, n$;

$B$ - the maximum amount that can be invested in all projects by the regional administration

$r_{i}$ - rating of the i-project for a NM where $r_{i}$ can vary from 1 to $\mathrm{n}$, and the highest rating corresponds the meaning $r_{i}=1$;

$s_{i}$ - rating of the i-project for the regional administration.

The i-project internal parameters are allotted in a separate group. The nodes that take part in the cooperation of developing program are designated through the $\underbrace{P_{1}, \ldots, P_{l}}_{\text {enterprises }}, \underbrace{P_{l+1}, \ldots, P_{m}}_{\text {banks }}, \underbrace{P_{m+1}, \ldots, P_{n}}_{\text {government }}$. The figure 2 shows the nodes split along sandwich-model planes according to their activity fields. 


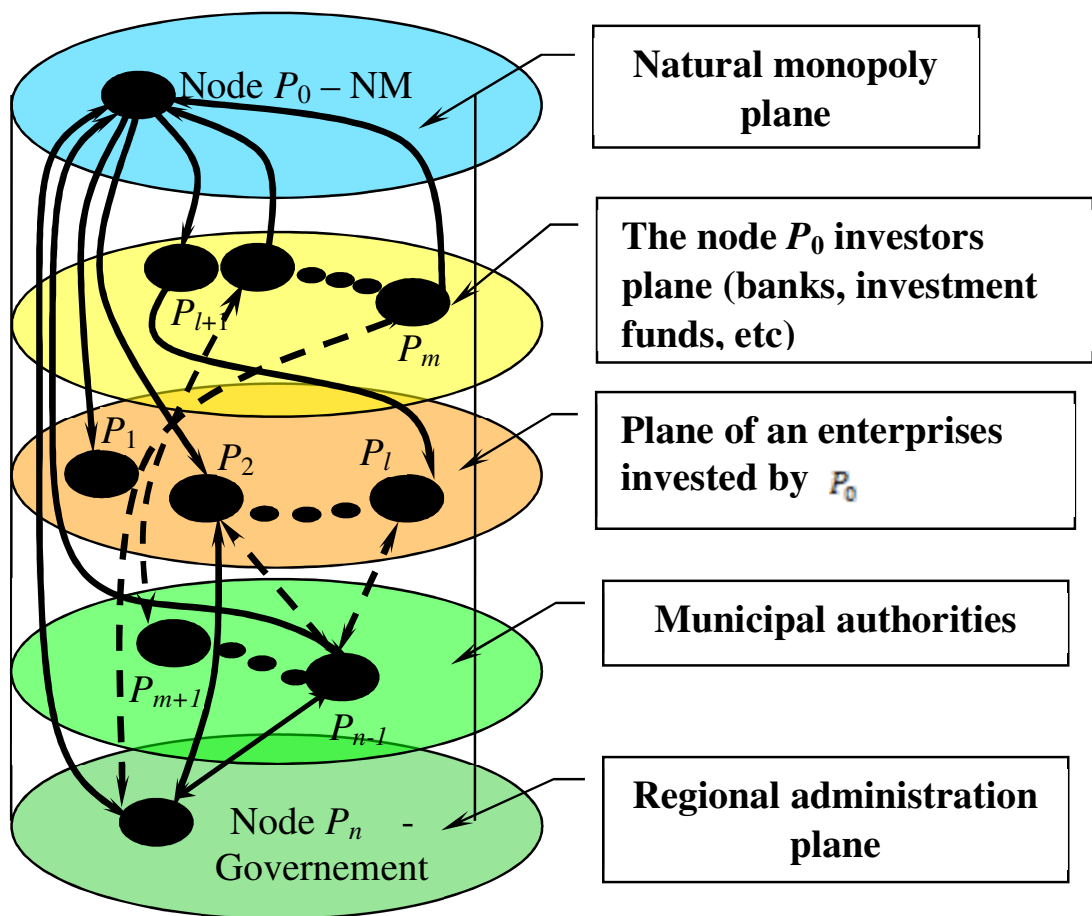

Fig.2. The nodes split along sandwich-model planes according to their activity fields

The internal i-project parameters can be divided into two blocks. The first one is data collected and calculated against a NM, i.e. the node $P_{0}$, the second one is data related to the regional administration, i.e. the node $P_{n}$.

\section{Effectiveness ratio calculation methodology of the regional authorities and the NM}

The internal i-project parameters that influence to decision-making about launching the cooperation program with the node $P_{0}\left(P_{0}\right.$ is a $\left.\mathrm{NM}\right)$ are the following: node $P_{\delta}$;

$t_{\text {land }}^{j}$ - the time of landing a node $P_{j} \in\left\{P_{1}, P_{2}, \ldots, P_{l}, P_{m+1}, \ldots, P_{n-1}\right\}$ by the

$S_{\text {lend }}^{j}$ - the lending volume of a node $P_{j} \in\left\{P_{1}, P_{2}, \ldots, P_{l}, P_{m+1}, \ldots, P_{n-1}\right\}$ in \$, implemented by a NM company's own funds;

$S_{\text {im }}^{(j)}$ - the immediate income of the node $P_{\delta}$ from the node $P_{j}$;

$R_{\text {loss }}^{j}$ - the actual losses of the node $P_{\delta}$ from the interaction with the node $P_{j}$ (according to prices level to date); 
$p_{j}$ - the stability factor of a partner node $P_{j}$ invested by both the own funds of node $P_{\delta}$ and the debt funds;

$\Delta v^{(j)}$ - the overall growth of the considered outputs on the invested node $P_{j}$, planned as the result of appropriate project implementation on the node $P_{j} \in$ $\left\{P_{1}, P_{2}, \ldots, P_{l}, P_{m+1}, \ldots, P_{n-1}\right\}$ (implementation the appropriate regional or territorial program);

$D_{\text {bank }}^{j}$ - the potential guaranteed income from the alternative putting own funds of node $P_{\delta}$ into a bank account that were allocated to the $P_{j}$ enterprise project implementation;

$0<\lambda_{j}<1$ - the extent of linkage of the node $P_{j}$ implementing project with other projects and regional programs;

Among the internal i-project parameters that have to be considered first and foremost during the regional interests' assessment, one has to have data about the predicted parameters value change in the case of program implementation, defining its solvency:

$\Delta M_{\text {reg }}^{i}$ - the change in export from the region, \$/year;

$\Delta V_{\text {reg }}^{i}$ - the change in import in the region, \$/year;

$\Delta B_{\text {reg }}^{i}$ - the change of regional budget volume, \$/year;

$\Delta N_{\text {reg }}^{i}$ - the population change in the region, people;

$\Delta S_{\text {reg }}^{i}$ - the change in the workplaces number, sq.km.;

$\Delta L_{r e g}^{i}$ - the change of population loyalty, $\mathrm{km}$;

$\Delta \Phi_{\text {reg }}^{i}$ - the Federal impact factor (subsidies) for the region (\$/year).

Obtainment all mentioned above data should not pose a problem because in practice, the NM is aware of importance and impact of each certain project to the regional economy when cooperation programs are being agreed.

In fact, participatory share of the parties in each project and efficiency and solvency depending on it, have to be reconciled by high-performance cooperation program configuration of a NM and certain subject of the RF. This is defined by the following parameters:

$x_{i}$ - the amount of funds allocated to the i-project NM, where $i=1,2, \ldots, n$;

$y_{i}$ - the amount of funds allocated to the i-project be the regional administration, where $i=1,2, \ldots, n$;

To calculate the efficiency of the program, the program should be presented as a one "large" project, where for its implementation all tasks that are necessary for each separate project implementation have to be completed.

In this case, one can consider both the effectiveness ratio and the rate of program solvency change depending on the considered situation $(\mathrm{x}, \mathrm{y})$ and they can be expressed respectively as $k(x, y)$ and $\Delta W(x, y)$. Hence, the projected income for the NM can be expressed by the formula: 


$$
\begin{aligned}
D(x, y) & =\frac{1}{T} \sum_{i=1}^{T}\left(\sum_{j=1}^{s}\left(\left(\left(S_{\mathrm{im}}^{(j)}\right)_{i}+\alpha_{j} \cdot\left(\Delta v^{(j)}\right)_{i}\right) \cdot p_{j} \cdot \frac{1+\lambda_{j}}{2}\right)+\right. \\
& \left.+\sum_{j=s+1}^{n-m+l}\left(\left(\left(R_{\text {loss }}^{j}\right)_{i}+\alpha_{j} \cdot\left(\Delta v^{(j)}\right)_{i}\right) \cdot p_{j} \cdot \frac{1+\lambda_{j}}{2}\right)\right)
\end{aligned}
$$

Then the overall effectiveness ratio of the NM program in the case $(\mathrm{x}, \mathrm{y})$ is:

$$
k(x, y)=\frac{D(x, y)}{D(x, y)+\frac{1}{T} \sum_{i=1}^{T}\left(\sum_{j=1}^{s}\left(D_{\text {bank }}^{j}\right)_{i}\right)+\frac{1}{T} \sum_{i=1}^{T}\left(\sum_{j=s+1}^{n-m+l}\left|\left(R_{\text {loss }}^{j}\right)_{i}\right|\right)}
$$

In the same way the ratios for the second party of interaction in the case $(\mathrm{x}, \mathrm{y})-$ regional administration - are:

$\Delta W(x, y)=\sum_{i=1}^{n}\left(\alpha_{1} M_{r e g}^{i}+\alpha_{2} V_{r e g}^{i}+\alpha_{3} B_{r e g}^{i}+\alpha_{4} N_{r e g}^{i}+\alpha_{5} S_{r e g}^{i}+\alpha_{6} L_{r e g}^{i}+\alpha_{7} \Phi_{r e g}^{i}\right)$

\section{Math model of development and reconciling cooperation programs}

Now there is a problem to find a situation $(\mathrm{x}, \mathrm{y})$, where the efficiency $k(x, y)$ satisfies the $\mathrm{NM}$, and the solvency change $\Delta W(x, y)$ meets the regional administration's requirements, i.e. the common cooperation program in the configuration $(\mathrm{x}, \mathrm{y})$ can be accepted by both sides.

To solve the problem of searching the suitable situation $(\mathrm{x}, \mathrm{y})$ the best variant is game theory. Its mathematical apparatus allows choosing according to some criteria variants from all possible number of variants that satisfy both parties according to formulated interests of parties-players.

The function named as the Rating of the situation $(\mathrm{x}, \mathrm{y})$ for the regional administration $R_{n}(x, y)$ is defined analogically.

Among all the situations $z_{k}=\left(x^{(k)}, y^{(k)}\right)$, where $k=1, \ldots, m$, obtained during solving the linear programming problem, let's choose the situations that are optimal according to Pareto criterion [4-8], i.e. the situations $z^{*}=\left(x^{*}, y^{*}\right)$ where there are no more preferred for both players situations $z=(x, y)$, i.e. such that:

$$
\begin{aligned}
& k\left(x^{*}, y^{*}\right) \leq k(x, y), \Delta W\left(x^{*}, y^{*}\right) \leq \Delta W(x, y), \\
& R_{0}\left(x^{*}, y^{*}\right) \geq R_{0}(x, y), R_{n}\left(x^{*}, y^{*}\right) \geq R_{n}(x, y) .
\end{aligned}
$$

Here $R_{0}(x, y)$ is the rating of situation $(\mathrm{x}, \mathrm{y})$ for the $\mathrm{NM}$,

$R_{n}(x, y)$ is the rating of situation (x,y) for the regional administration.

According to the results of problem solving there is a set of Pareto efficiency situations $z^{*}=\left(x^{*}, y^{*}\right)$ 
By means of negotiations and discussion on the basis of calculations made above, from the limited set one can choose such situation, i.e. the configuration of the common program, that satisfies both parties by the effectiveness ratio and solvency, and, hence, by the income level, expenditure level and its influence for the socio-economic performance of the region.

\section{References}

[1] Шутюк С.В., Сай В.М., Афанасьева Н.А., Математическая модель согласования программ развития ОАО «РЖД» в регионе и субъекта РФ, Экономика железных дорог, № 4, 2005.

[2] S. Vikharev, Comparative vendor score, Applied Mathematical Sciences, 7, 2013, 4949-4952.

[3] A. Sheka, Verification and validation of the comparative vendor score, Applied Mathematical Sciences, 7, 2013, 4953-4959.

[4] Zheng, J., Xu, F., Monopoly supplier's negotiation strategy and its impact on supply chain efficiency, BMEI 2011 - Proceedings 2011 International Conference on Business Management and Electronic Information, 5, 2011, 278-282.

[5] Niu, D.-X., Wei, Y.-N., Li, J.-Q., Xu, C., Wu, J.-F., Game analysis of inter-regional electricity trade cooperative based on shapley model, Proceedings of the International Conference on E-Business and E-Government, ICEE 2010, 2010, 4078-4080.

[6] Calzolari, G., Pavan, A., On the optimality of privacy in sequential contracting, Journal of Economic Theory, 130 (1), 2006,168-204.

[7] Lopes, F., Coelho, H., Multi-agent negotiation in electricity markets, Lecture Notes in Business Information Processing, 85 LNBIP, 2011, 114-123.

[8] Toshimitsu, T., A Note on the Endogenous Timing of Tariff Policy in the Presence of a Time Lag between Production and Trade Decisions, Open Economies Review, 24 (2), 2013,361-369.

\section{Received: August 23, 2013}

